\title{
Persuasive Phytochemical Screening for Antioxidant Activity of Catharanthus roseus L. (Whole Plant)
}

\author{
Saroj Yadav ${ }^{1 a}$, Tuleen Rodrigues ${ }^{1}$, Harsha Vardhan Reddy ${ }^{1}$, Sushil Pandey ${ }^{1}$, Archana Singh ${ }^{1}$, Om Prakash $^{2 *}$ \\ ${ }^{1}$ SRM College of Pharmacy, SRM University, Kattankulathur, Tamil Nadu, India \\ ${ }^{\text {a }}$ Allied to AKTU, Lucknow, India, ${ }^{2}$ R\&D-Lotus herbals Pvt. Ltd. New Delhi, India
}

\begin{abstract}
Oxidative reactive species play an important role in pathological conditions such as aging, fatty liver and cancers. Secondary metabolites enriched fraction derived from medicinal plants showed the inhibition of free radical generation by playing an important role in precluding various diseases. The aim of present study was to evaluate the antioxidant activity of different extracts by using the DPPH method. We assayed the free radicals scavenging activity of extracts at 50, 100, 200, 400 and $500 \mu \mathrm{g} / \mathrm{ml}$ concentration and phytochemical study of Petroleum ether, Chloroform, Methanol and Aqueous whole plant extracts of Catharanthus roseus. Amid the five absorption concentrations tested, it was observed that dose of 500 $\mu \mathrm{g} / \mathrm{ml}$ showed the higher antioxidant activity for each extract. All samples displayed an increasing antioxidant effect with increase in concentration i.e. concentration dependant. The IC50 value of Petroleum ether, Chloroform, Methanol and Aqueous extract was found as 330.73 $\mu \mathrm{g} / \mathrm{ml}, 596.13 \mu \mathrm{g} / \mathrm{ml}, 801.92 \mu \mathrm{g} / \mathrm{ml}$ and 504.12 $\mu \mathrm{g} / \mathrm{ml}$ respectively. The petroleum ether extract at the concentration of $500 \mu \mathrm{g} / \mathrm{ml}$ showed the highest \% inhibition of $67.441 \%$ compare to other extracts. DPPH method provides an easy and fast way to analyze potential antioxidants. The $C$. roseus extracts can be considered a rich natural source of antioxidants and can be used to develop pharmaceutical products for therapeutic treatment of various disorders caused by free radicals in human body.
\end{abstract}

Keywords:- Antioxidant; DPPH; Free radical.

\section{INTRODUCTION}

Catharanthus roseus L. (Famaily: Apocynaceae) is a perennial plant and commonly known as Madagascar Periwinkle is seen in tropical counties and are native to Southern Asia and Madagascar but now widely dispersed in the tropics [1]. This plant has the ability to synthesize a wide-range of terpenoid indol alkaloid with medicinal values. These alkaloid compounds have a wide application in the treatment of leukemia in children, and lymphocytic leukemia, neuroblastoma, Wilkins's tumor and Hodgkin's disease. [2].
About more than $50 \%$ of the modern therapeutic agents having anti-tumor activity were obtained from medicinal plants by using chromatographic techniques or one of the ingredients required to synthesize drug is derived from the natural sources eg. vinblastine, and vincristine, were isolated from vinca plant and characterized using NMR techniques.

Antioxidants "free-radical scavengers"are substances that can prevent or slow damage to cells caused by free radicals in the body can be internal, such as inflammation, or external, for example, pollution, UV exposure, and cigarette smoke. The sources of antioxidants can be natural i.e. plant based or artificial. Endogenous antioxidants are produced naturally by the body to protect against free radicals generated inside body. Exogenous antioxidants are taken as a dietary supplement from outside the body. Oxidative stress has been linked to heart disease, cancer, arthritis, stroke, respiratory diseases, immune deficiency, emphysema, Parkinson's disease, and other inflammatory or ischemic conditions. Antioxidants can neutralize free radicals inside our bodies, and results into improvement of overall health. Plants and herbs are vibrant part of human since ancient times. Medicinal plants are the godsend of wildlife for the management of numeral disorders generated inside the body.

Oxidative stress happens as the result of an imbalance between the internal production of free radicals and the antioxidant defence mechanisms of living organisms. When the level of free radicals is increased and low molecular antioxidants are not adequate to protect the organism, free radicals are formed in surplus to induce cellular damage and therfore actively participate in the development of diseases [3-4]. Antioxidant enzymes such as catalase, glutamine peroxidase, and superoxide dismutase act to reduce the cellular level of free radicals. However, antioxidant supplementation is often necessary to limit the deleterious effects of the excess free radicals which have been formed. Among the natural products with antioxidant properties, alkaloid compounds have been concisely studied. Because these compounds neutralize free radicals and inhibit lipid oxidation, they inhibit the formation of toxins such as malondialdehyde (MDA). Such alkaloid compounds are particularly useful in the treatment of different disorders like cancer, diabetes etc. Previous studies have shown that aqueous extract of the root of $C$. roseus has good antioxidant properties [5-6]. 
The aim of present research study is to provide scientific proof by persuasive investigative the antioxidant activity of different extracts prepared using whole plant and also linking the antioxidant activity of whole plant extracts and alkaloids isolated by Tiong et al.[7] using phytochemical and in vitro assays. The antioxidant potential of whole plant extract has been compared with some of the reported alkaloids (Fig. 1).
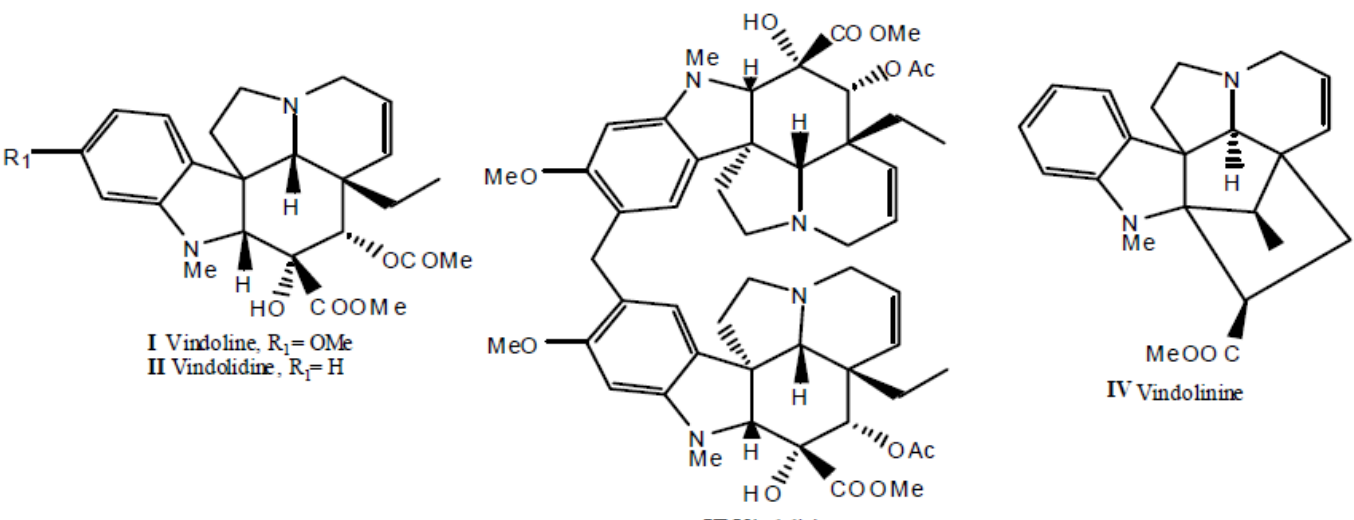

IV Vindolinine

Fig 1:- Chemical Structure of Alkaloids isolated from Leaves of C. roseus

\section{MATERIALS AND METHODS}

\section{A. Plant Material:}

The selected whole plant of Catharanthus roseus L. were collected from SRM College Of Pharmacy, SRM University Kattankulathur ,Tamil Nadu, India in the month of October, 2016. The Whole plant was taxonomically identified by Professor Dr. Jayaraman, Taxonomist, Chennai.

\section{B. Preparation of Plant Extracts:}

The whole plant of $C$. roseus was air-dried under shade for seven days. The dried plant material was taken and ground to fine powder. A bulk of $137 \mathrm{~g}$ of dried powder was fully extracted with $1 \mathrm{~L}$ of Petroleum ether, Chloroform, methanol and D.M Water separately by using Soxhlet apparatus. The each solvent obtained by filteration was evaporated under reduced pressure using a rotary evaporator at $40-45^{\circ} \mathrm{C}$ except water. Water was evaporated on heating plate to give extract (Fig. 2).

Whole plant of Catharanthus roseus<smiles>C=CC=C</smiles>

Dry in shade at room temperature<smiles>C=[Te]</smiles>

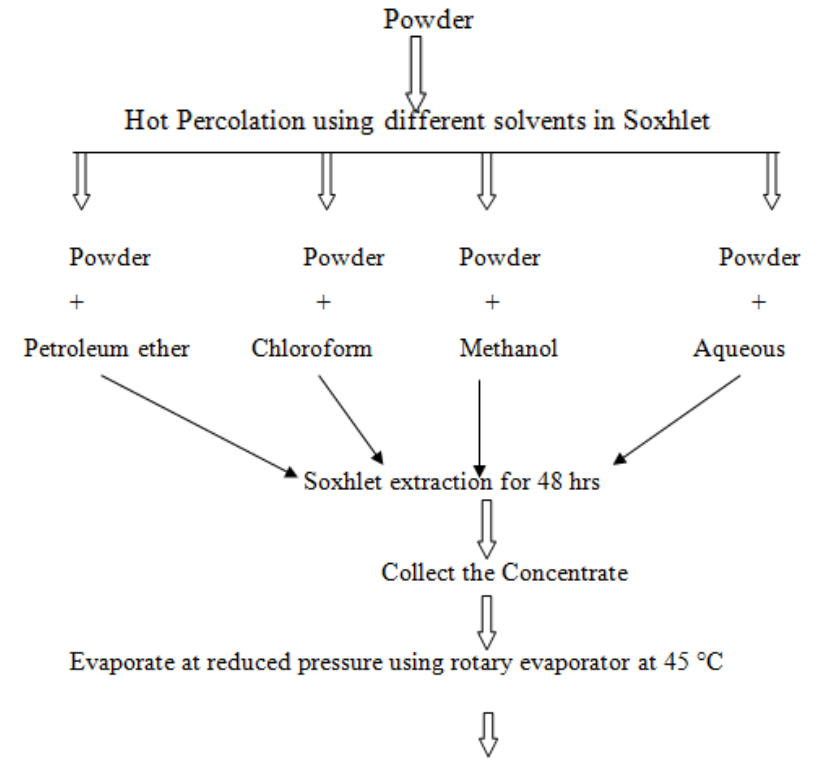

Collect the extract and store in air tight container

Fig 2:- Flow Chart for Preparation of Extracts 


\section{Phytochemical Analysis:}

The whole plant $C$. roseus extracts were standaradized qualitatively for the presence of different moiety of plant secondary metabolites [8-11]. These natural compounds have simple structure to complex substances and categorized into group of compounds based on the chemical moiety present in plant.

\section{Alkaloids:}

- Wagner's Reagent Test:

To a acidic solution of extract add Wagner's reragent (Solution of Iodine in Potassium iodide). The reaction of extract with Wagener reagents will develop a reddishbrown precipitate.

\section{- Test for Flavonoids:}

Flavonoids which occur both in the free state and as glycosides are the largest group of naturally occurring phenols. Take sample and dilute $(\mathrm{HCl})$ sideways with a small slice of zinc/magnesium. The reaction mixture was heated for 1-2 minutes in a test tube. The Reddish pink or dirty brown color confirms the presence of Flavonoids in the test sample.

\section{- Test for Carbohydrates:}

To a heated solution of the extract add mixture of equal parts of Fehling's solutions A and B. The reduction takes place near the boiling point and is shown by brick-red precipitate of cuprous oxides..

\section{- Benedict's Test:}

Take $0.5 \mathrm{ml}$ of extract, add $5 \mathrm{ml}$ of Benedict's reagent and boil it for $5 \mathrm{~min}$ in a test tube. If the reaction mixture is converted into a bluish green color, it means the carbohydrates are present in the extract.

\section{- Test for Phenols:}

To the approx. $1 \mathrm{ml}$ of sample of extract we have to add approx. $2 \mathrm{ml}$ of distilled water. To this solution slowly add a few drops of $10 \%$ Aqueous Ferric Chloride $\left(\mathrm{FeCl}_{3}\right)$ solution. After reaction is completed the reaction mixture will develop a blue or green precipitate which confirms the presence of phenols.

\section{- Test for Saponin Glycosides by Foam Test:}

Take about 3-5 $\mathrm{ml}$ of sample extract and add a $0.5 \mathrm{ml}$ of sodium bicarbonate to it. The reaction mixture was mixed by shaking forcefully and kept aside for 3-4 min. If the reaction mixture develops a honeycomb like froth, it will confirm the presence of saponins in the test sample of extract.

\section{Test for Cardiac glycosides}

- Legal's test

Take the extract solution in test tube and add $1 \mathrm{ml}$ pyridine and $1 \mathrm{ml}$ sodium nitroprusside to it. The reaction mixture develops pink to red color in the presence of cardiac glycosides.

\section{Test for Anthraquinone glycoside:}

- Bontrager's Test:

Take plant extract and boil it with $5 \mathrm{ml}$ of $10 \%$ sulfuric acid for two-three minutes. Filter it using filter paper in hot conditions. Cool the solution obtained after filtration i.e. filtrate and add equal volume of benzene, shake it vigorously for few minutes. After shaking is stoped the benzene layer was separately collected and half of its volume of solution ammonia (10\%) was added to it. Again it is shaken well and allowed to separate. If the Ammonia (Alkaline) Layer developed pink or red color it showed the positive result for the presence of anthraquinones.

\section{- Detection of Tannins by Lead Acetate Test:}

Add 4-5 $\mathrm{ml}$ of extract sample to the test tube and a few drops of $1 \%$ solution of lead acetate to the extract. If reaction mixture gives Yellow or red precipitate, it showed the positive test for the tannins in extract.

\section{- Phyto-sterols/ Lipids:}

Add about $0.5 \mathrm{ml}$ of the extract into a test tube and mix it with a few drops of chloroform. Add approx. $1 \mathrm{ml}$ of acetic acid and approx. $0.5 \mathrm{ml}$ drop of concentrated sulphuric acid. The development of a deep blue or green color indicates the presence of steroids in extract.

\section{$>$ Test for Protein:}

- Biuret test:

Add 2-3 ml of extract solution into a test tube, add equal volume of $10 \%$ solution of sodium hydroxide. Shake it vigorously, add $0.5 \%$ solution of copper sulphate slowly drop by drop, until a purplish violet or pinkish colour is developed.

\section{Determination of Antioxidant Activity:}

The radical scavenging activity of the plant extract was determined using DPPH method [12-13]. All the experiments were carried out in triplicate. About $20 \mu \mathrm{g} / \mathrm{ml}$ concentration solution of DPPH reagent was prepared by dissolving it in methanol. Take $6 \mathrm{ml}$ solution of the prepared DPPH solution and mix it separately with different concentration $(50,100,200,400,500 \mu \mathrm{g})$ of $C$. roseus extract $(20 \mu \mathrm{l}$ solution) at room temperature. The DPPH and Plant extract mixture to be shaken vigorously for 5 minutes and absorbance of reaction mixture was measured at about $517 \mathrm{~nm}$ using UV-Visible spectrophotometer.

The following equation was used to convert the absorbance values into percentage inhibition antioxidant activity:

$\%$ Inhibition Activity $=[($ Absorbance of $\mathrm{B}-$ Absorbance of T)/ Absorbance of B] $\times 100$

B: Observed absorption of Blank Sample; T: Observed absorption of Tested samples. 
The half inhibitory concentration $\left(\mathrm{IC}_{50}\right)$ of the different extracts was determined as DPPH scavenging activity. Ascorbic acid solution was prepared and used as standard in this DPPH assay.

Statistical Analysis: The experiments were carried out in triplicate, and the statistical software was used for the developing statistical analysis.

\section{RESULTS AND DISCUSSION}

The phytochemical investigation of the different extracts of whole plant of C.roseus confirmed the presence of Phytochemical viz. secondary metabolites. The Medicinal plants are used for developing therapeutic agent as these plants contained many active compounds like alkaloids, Flavonoids and Phenolic etc. This study publicized that the occurrence of Phyto-active compounds like carbohydrates, flavonoids, phenols, phytosterols, alkaloids, saponins, tannins in the different extract of plant. The different whole plant extracts $C$. roseus was further studied for antioxidant properties. The result shows Table 1 the presence of alkaloids in different extracts.

\begin{tabular}{|c|c|c|c|c|c|}
\hline \multirow[t]{2}{*}{ S. No. } & \multirow{2}{*}{$\begin{array}{c}\text { Phytochemicals/ Secondary } \\
\text { Metabolites }\end{array}$} & \multicolumn{4}{|c|}{ Results } \\
\hline & & Petroleum Ether & Chloroform & Methanol & Aqueous \\
\hline 1 & Alkaloids & + & + & + & + \\
\hline \multirow[t]{4}{*}{2} & \multicolumn{5}{|c|}{ Glycosides } \\
\hline & i)Saponin & - & - & + & + \\
\hline & ii)Anthraquinone & + & + & + & - \\
\hline & iii)Cardiac & + & + & + & + \\
\hline 3 & Tannins & + & + & + & + \\
\hline 4 & Carbohydrates & + & + & + & + \\
\hline 5 & Lipids/Phytosterols & + & + & + & - \\
\hline 6 & Proteins & - & - & - & - \\
\hline 7 & Flavanoid & - & + & + & - \\
\hline 8 & Phenolic Compound & - & + & + & + \\
\hline
\end{tabular}

Table 1:- Qualitative phytochemical screening of whole plant of Catharanthus roseus.

These phytoconstituents are used for the synthesis of many clinically approved dugs as they act as biologically active when taken internally. For example, many physiological activities such as host-mediated tumor activity, stimulation of phagocytic cells and a wide range of anti-infection activities are assigned to tannins. Tannin containing medicinal plants are exhibiting astringent activity and used for the management of dysentery and diarrhoea. Alkaloids present in plants exhibit noticeable physiological effects and hence their extensive use in developing medicine or drugs. Medicinal plants containing various phytochemicals are considered as important therapeutic targets of patent claims in the pharmaceutical drug and cosmetics industry.

In this research it was investigated that the different extracts of Whole Plant $C$. roseus was showing the free radical scavenging activity by DPPH radical scavenging assay. Whole plant extracts showed excellent radical scavenging activity. To best of our information, no earlier reports are available regarding the DPPH radical scavenging activity of $C$. roseus whole plant correlating with alkaloids. There are a few evidence that biologically active compounds from plants have proficient anti- oxidative properties, subsequently linked to anti-aging, anti-inflammatory anti-cancer, and hypolipidemic, activities [8].

The present research study demonstrating that antioxidant activity of whole plant extracts of $C$. roseus at different concentrations 50,100, 200, 400 and $500 \mu \mathrm{g} / \mathrm{ml}$ was determined by DPPH assays. Out of the tested concentrations, $500 \mu \mathrm{g} / \mathrm{ml}$ showed the overall superior antioxidant activity for each whole plant extract. The $\mathrm{IC}_{50}$ value indicates the concentration of extracts or standards at which $50 \%$ reduction in oxidative free radicals to be observed.

Lower the $\mathrm{IC}_{50}$ value higher will be the antioxidant activity of the plant extracts. All samples displayed an increasing antioxidant effect with increase in concentration i.e. concentration dependant. The $\mathrm{IC}_{50}$ value of Petroleum ether, Chloroform, Methanol and Aqueous extract was found as $330.73 \mu \mathrm{g} / \mathrm{ml}, 596.13 \mu \mathrm{g} / \mathrm{ml}, 801.92 \mu \mathrm{g} / \mathrm{ml}$ and $504.12 \mu \mathrm{g} / \mathrm{ml}$ respectively. The petroleum ether extract $(500 \mu \mathrm{g} / \mathrm{ml})$ showed the highest \% inhibition of $67.441 \%$ compare to other extracts. 


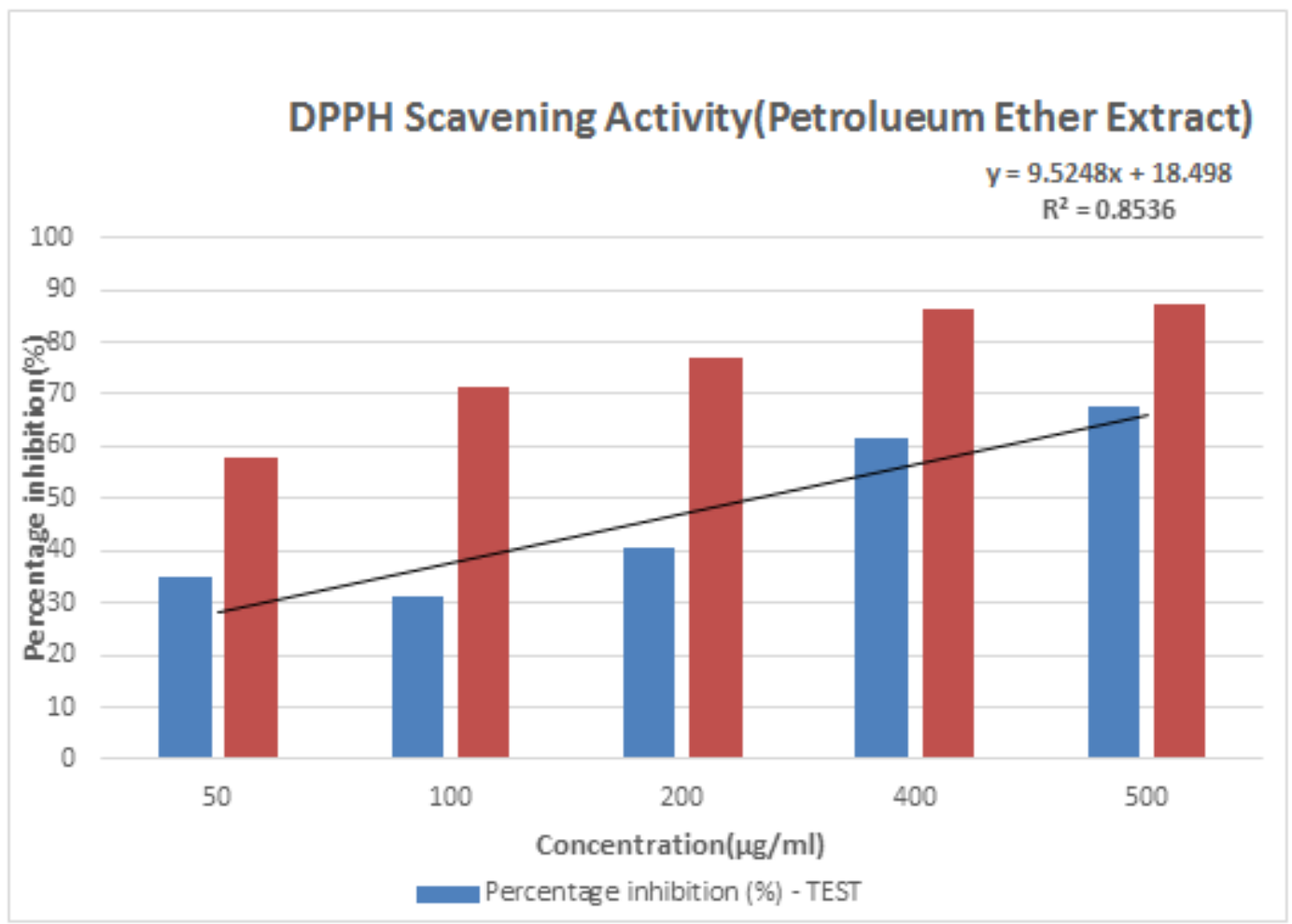

Fig 3:- Free radical Scavenging Activity (Petroleum ether Extract)

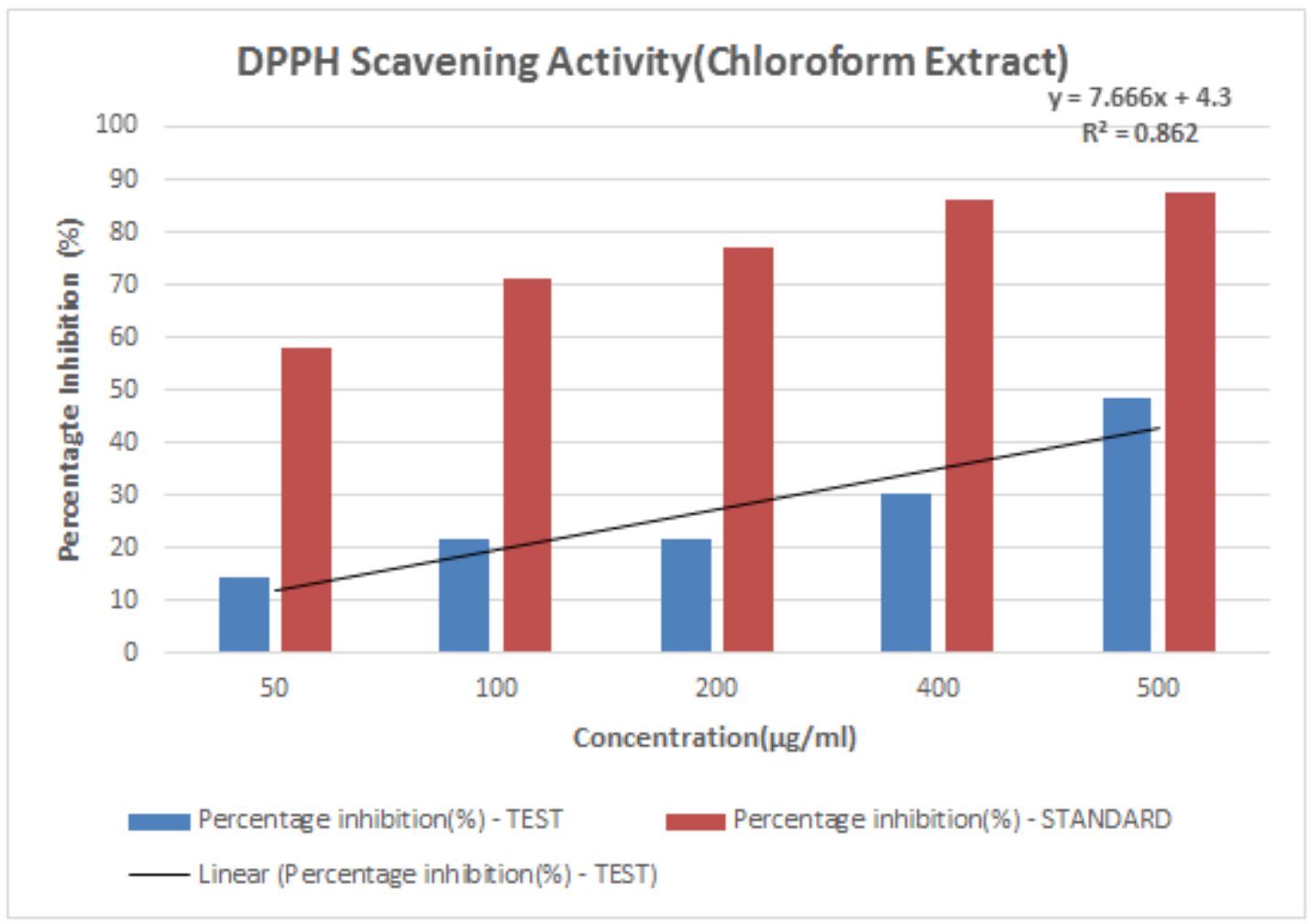

Fig 4:- Free radical Scavenging Activity (Chloroform Extract) 


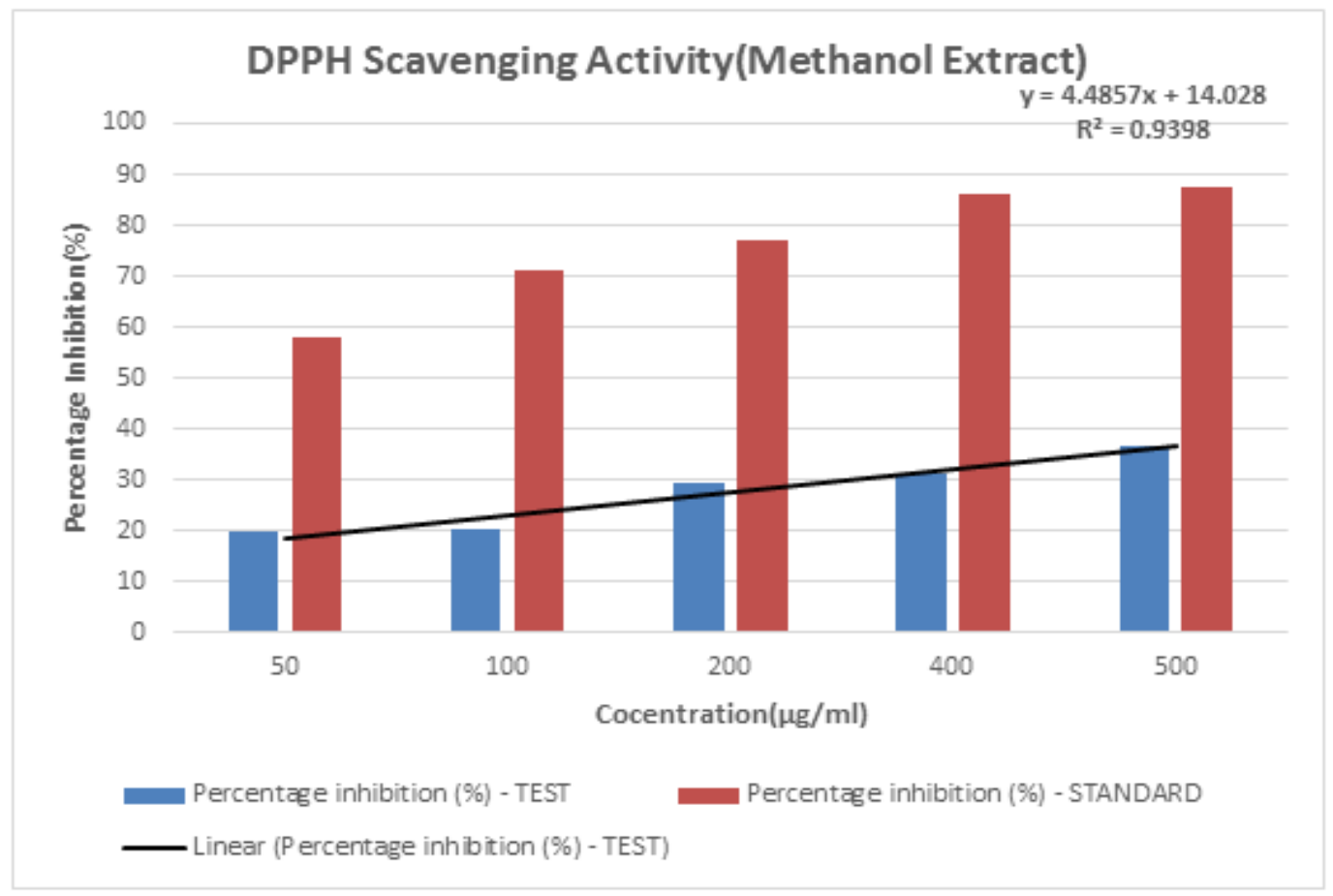

Fig 5:- Free radical Scavenging Activity (Methanol Extract)

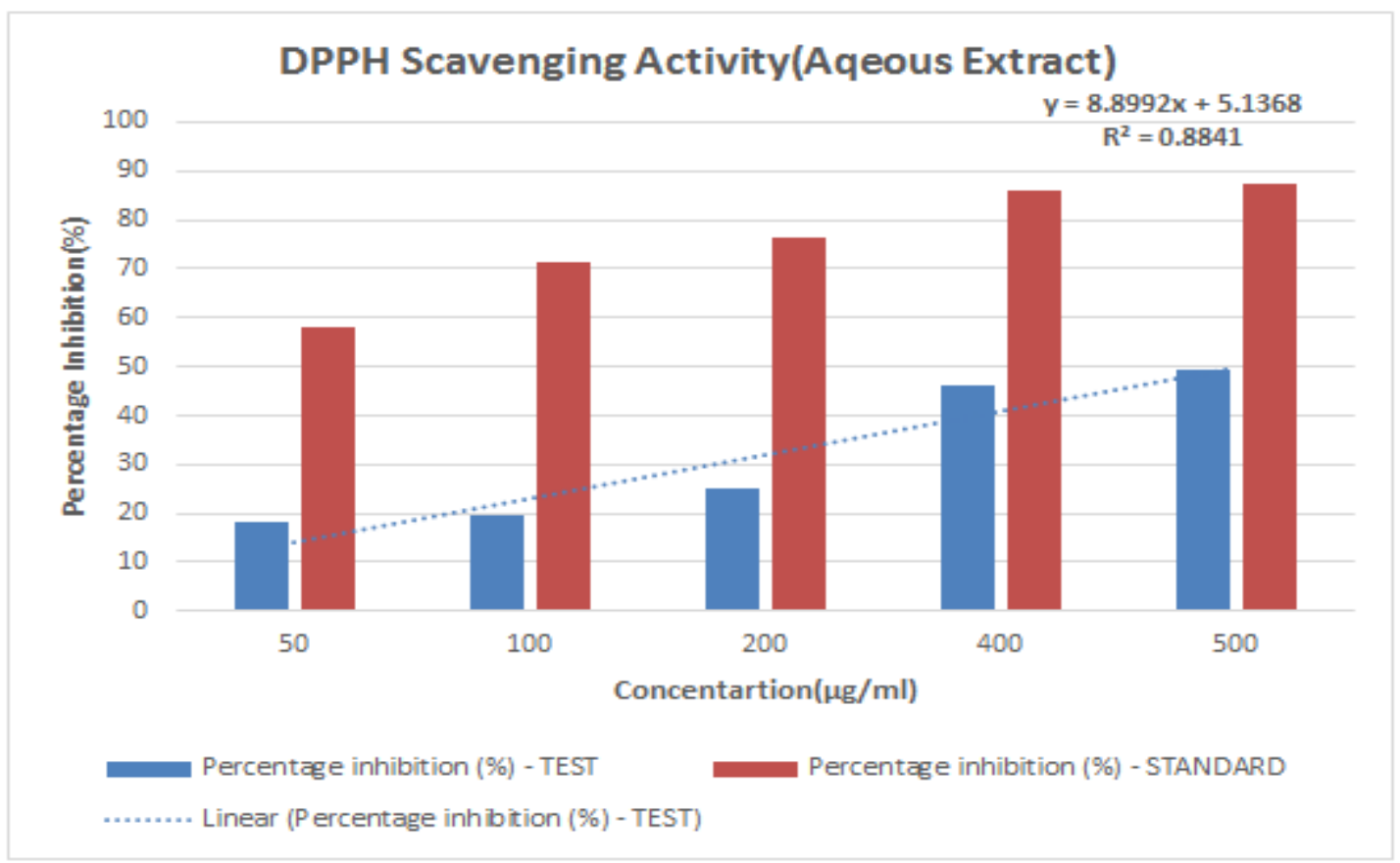

Fig 6:- Free radical Scavenging Activity (Aqueous Extract)

It was studied previously that the extract of C.roseus have the maximum ORAC antioxidant capacity out of several medicinal herbs tested, with ORAC values of 22.30 $\mu$ mol Trolox equivalent $(\mathrm{TE}) / \mathrm{g}$. In our study, the $\mathrm{IC}_{50}$ value of the aqueous whole plant extract was found to be $504.12 \mu \mathrm{g} / \mathrm{ml}$ which was slightly less than the $\mathrm{IC}_{50}$ value of the aqueous leaves extract as reported earlier [14-15].

DPPH inhibitory activity of the four reported alkaloids [8] viz. Vindolicine exhibited the highest DPPH inhibition activity $(52.9 \pm 12.0 \mu \mathrm{M})$, followed by Vindoline $(73.0 \pm 14.7 \mu \mathrm{M})$, Vindolidine $(91.1 \pm 20.9 \mu \mathrm{M})$, and vindolinine $(165.5 \pm 53.0 \mu \mathrm{M})$. This confirms that alkaloids present in different parts like leaves, roots, stem, flowers are also contributing to show the antioxidant activity along with other secondary metabolites.

Vinca alkaloids are having poisonous activities as well as biological effects too that makes them useful as drugs. The alkaloids are shown to be distributed in all parts of the plant. The maximum alkaloids are being present in the root bark particularly during flowering. The physiologically important alkaloids in the aerial parts of the plant are mainly antineoplastic dimeric alkaloids, 
vinblastine, vincristine and roots contains mainly ajmalicine, serpentine. Another alkaloid, vinflunine having anti-tumour activity, but it is not universally accepted except in Europe. Vincristine and Vinblastine are chemotherapy medications used to deal with several types of cancers and are biosynthesised from the linking of the alkaloids catharanthine and vindoline. The newer semisynthetic chemotherapeutic agent vinorelbine is used to deal with lung cancer, can be synthesized either from vindoline and catharanthine or from the vinca alkaloid leurosine in both cases via anhydrovinblastine. The flower of $C$. roseus contains Rosinidin which is an anthocyanidin pigment [16-17].

\section{CONCLUSION}

The modern chemotherapeutic agents for their painrelieving properties are also produced by the vinca plant. Hence, it can be considered medically important plant for development of new therapeutic drugs to be effective aginst various diseases. The whole plant of $C$. roseus was studied for the phytochemical and antioxidant activity. The result indicated that petroleum ether extract possesses the superior antioxidant and phytochemical activity which may be due to synergistic effect of alkaloids along with other secondary metabolites. However, further pharmacological and toxicity studies to be explored so that the new secondary metabolic compounds of this plant can be converted into medicine. This study established that $C$. roseus whole plant extract may be considered as a useful enriched fraction for developing therapeutic products for application as an antioxidant and phytochemical agent.

\section{ACKNOWLEDGMENT}

We would like to express sincere thanks to the Dean SRM College of Pharmacy SRM University, Kattankulathur, Tamil Nadu, India for providing the required chemicals and facility for our project.

\section{REFERENCES}

[1]. Lata B. Cultivation, mineral nutrition and seed production of Catharanthus roseus (L.) G. Don in the temperate climate zone. Phytochem Rev. (2007) 6: 403-11.

[2]. Aslam J, Khan SH, Siddiqui ZH, Fatima Z, Maqsood M, Bhat MA, Nasim SA, Ilah A, Ahmed IZ, Khan SA, Mujib A and Sharma MP. Catharanthus roseus L. an important drug: its applications and production. Pharma Globale. (2010) 1: 1-16.

[3]. Lobo V., Patil A, Phatak A. and Chandara N. Free radicals, antioxidants and functional foods: Impact on human health. Pharmacogn Rev. (2010) 4: 118-126.

[4]. Shaw C.A, Taylor EL, Megson I.L and Rossi A.G. Nitric oxide and the resolution of inflammation: implications for atherosclerosis. Mem Inst Oswaldo Cruz. (2005) 1: 67-71.
[5]. Pereira D.M, Faria J, Gasparn L, Ferreres F, Valentao $\mathrm{P}$, Sottomayor $\mathrm{M}$ and Andrade PB. Exploiting Catharanthus roseus roots: source of antioxidants. Food chem. (2010) 121: 56-61.

[6]. Ferreres F, Pereira D.M, Valentao P,. Andrade P.B, Seabra RM and Sottomayor M. New phenolic compounds and antioxidant potential of Chataranthus roseus. J Agr Food Chem. (2008) 56: 9967-9974.

[7]. Tiong S.H., Looi C.Y., Hazni H., Arya A., Paydar M., Wong W.F., Shiau-Chuen Cheah, Mustafa M.R., Awang K.. Antidiabetic and Antioxidant Properties of Alkaloids from Catharanthus roseus (L.) G. Don. Molecules 2013, 18, 9770-9784.

[8]. Kapoor L.D, Singh A., Kapoor S.L. Srivastava S.N: Survey of Indian medicinal plants for saponins, alkaloids and flavanoids. Lloydia. 1969, 32: 297-302.

[9]. Somolenski S.J., Silinis H. Farnsworth N.K: Alkaloids Screening. I, Lloydia 1972; 35: 1-34.

[10]. Kokate C.K: Practical Pharmacognosy. Valla PB Prakshan. New Delhi, 4th Edition, 1994; 179-181.

[11]. Trease, G.E. and Evans, W.C. (1989) A Text-Book of Pharmacognosy. Bailliere Tindall Ltd., London, 53.

[12]. Yadav S. and Kumar A. Antioxidan activity of free and bound phenolics in Curcuma longa. International Journal of Phytomedicine,2013, 5 (1) 58-61.

[13]. Schmeda-Hirschmann G., Razmilic I., Gutierrez M.I, Loyola J.I. Proximate composition and biological activity of food plants gathered by Chilean Amerindians. Econ. Bot., 1999; 53:177-187.

[14]. Zheng, W.; Wang, S.Y. Antioxidant activity and phenolic compounds in selected herbs. J. Agric.Food Chem. 2001, 49, 5165-5170.

[15]. Ferreres, F.; Pereira, D.M.; Valentão, P.; Andrade, P.B.; Seabra, R.M.; Sottomayor, M. New phenolic compounds and antioxidant potential of Catharanthus roseus. J. Agric. Food Chem.2008; 56, 9967-9974.

[16]. Gajalakshmi S., et.al."Pharmacological activities of Catharanthus roseus: A Perspective Review". J. American Chemical Society, 2013; 4(2): 431-439.

[17]. Asma N., et.al. "An updated Review on Catharanthus roseus: Phytochemical and Pharmacological Analysis". Indian Res. J. Pharmacy Sci. 2016; 3(2): 631-653. 